\title{
Design of the Customer Expectation Measurement Model in Dynamic Service Experience Delivery
}

\author{
Yen-Hao Hsieh \\ Department of Information Management \\ Chia Nan University of Pharmacy and Science \\ Tainan, Taiwan \\ yhhsiehs@mail.chna.edu.tw \\ Soe-Tsyr Yuan \\ Department of Management Information Systems \\ National Chengchi University \\ Taipei, Taiwan \\ yuans@mis.nccu.edu.tw
}

\begin{abstract}
Customer-focused service design and innovation is critical in enabling service firms to deliver what customers want. Although numerous studies have emphasized the importance of customer expectations in numerous disciplines, previous empirical research has only captured non real-time data. Furthermore, previous research contains no mathematical mechanism for correctly catching customer expectations. Service firms therefore must make additional efforts to analyze and predict customer needs according to previous empirical research, yet their predictions and customer expectations continue to exhibit a significant gap. Accordingly, this study proposes a systematical and quantitative customer expectation measurement model based on Fechner's Law and the concepts of operation risk that service firms can use to measure real time customer expectations during service experience delivery.
\end{abstract}

Keywords: Customer expectation measurement, Service experiences delivery, Fechner's law, Service innovation. 


\section{Introduction}

Services increasingly dominate the economic activity and GDP of developed countries around the world. To strengthen their economic competitiveness, many countries are gradually increasing their investment in the service industry. However, the innovative services that customers desire and the means of delivering those services are important and complex issues. Sundbo (1997) mentioned that innovations can be considered a search-and-learning process that enables service firms to generate and gather unique ideas. Voss (2004) noted that the key innovation in service design is incorporating good experiences into services to increase customer repeat business. Despite lots of researchers from different disciplines, especially marketing, who have focused on several customer issues related to service innovation, including customer satisfaction, customer relationship management, customer expectation or customer loyalty, the problem of managing customer expectations is core issue influencing other customer issues.

Parasuraman et al. (1985) identified service quality as an area where a gap exists between customer expectations and perceptions of provided services. The theory of disconfirmation has also been applied to explain that customer satisfaction represents how closely services provided match customer expectations. Service firms attempt to eliminate the gap in the market for quality services by matching customer expectations to maximize customer satisfaction. High customer satisfaction results in customer loyalty and repeat custom for service firms (Heskett et al., 1994). That is, service firms can increase their profitability by maintaining long-term customer loyalty through achieving high customer satisfaction with provided services. Furthermore, customer expectations not only directly influence post-purposing behaviors and consumption evaluation but also influence customer beliefs regarding services (Gupta and Stewart, 1996; Spreng et al., 1996; Tam, 2007). Successfully providing customers with suitable services depends on how effectively service firms understand and manage customer expectations. Managing customer expectations is critical to achieving customer satisfaction (Pitt and Barbara, 1994). Parasuraman et al. (1991) also noticed that understanding customer expectations is necessary for service companies to deliver superior services and achieve competitive advantage and customer franchise. Accordingly, defining and implementing services that meet customer expectations increase the probability of enterprise success (Schurter and Towers, 2006). Designing good service experiences requires paying attention to managing customer expectations.

For service innovation, building good service operations can increase the opportunities for successful management of customer expectations. Good service experiences can be achieved through several high quality operational processes. Implementing these operational processes can ensure customers experience good and enjoyable service. Accordingly, service operation design attempts to create a good service environment and pleasant atmosphere for customers. Voss et al. (2008) proposed using service operations management architecture to clearly define four key strategic components of service experience delivery system (including stageware, orgware, customerware and linkware). The customerware strategy refers to managing customer encounters by using technology or employees to meet customer expectations. Managing customer expectations remains necessary for providing a good service experience.

Although issues related to customer expectations have long been discussed, few studies have applied the determinants of customer expectations. Service firms use the familiar empirical approaches (such as market survey, customer investigation or historical reports) to examine customer needs. Peppers et al. (1999) proposed that service firms can employ interactive and customized activities to understand real customer needs. However, these approaches are costly and time consuming, and the investigative results may not 
be sufficient to represent real customer needs during service experience delivery because previous research on operation design primarily employed non real-time data (such as questionnaire surveys or case study). Furthermore, previous research identified no systematic mechanisms for effectively measuring customer expectations (which are influenced by expectation determinants within service experience delivery) to manage the delivered service experience.

This investigation argues that measuring customer expectations is necessary to implement customer expectation management and operations service strategies designed to achieve good service experiences during service experience delivery. Accordingly, this study examines the following research question: How can service firms effectively and accurately measure customer expectations during service experience delivery?

This study proposes a theoretical customer expectation measurement model (so-called CEMM) for measuring real time customer expectations to understand actual customer expectations and behaviors, which considers several important concepts, including customer expectation, operation design, and so on, in fulfilling the service experience innovation. The traditional method of identifying customer expectations is through direct inquiries to customers either before or after service experience delivery. Service firms have difficulty flexibly deciding to dispatch suitable services during service experience delivery. In contrast, since service firms understand customer expectations and influence those expectations through providing appropriate services in real time, they can dynamically adjust the process of service experience delivery (for example, improving failure rates or improving service levels) to help ensure satisfactory customer service experience.

However, customer expectations, which are difficult to measure in terms of manipulation biases, cannot be numerically represented and calculated using customer external behaviors. Fechner's Law (Thurstone, 1929) is thus adopted to provide the psychological theory to underlie CEMM for quantifying customer expectations during service experience delivery. The concept of operation risk (which is based on the probability concept) is used to portray the effect of external stimuli (namely, expectation tactics and service operations) on customer expectations. The main contribution of this study thus is to integrate the theories of Fechner's Law and operation risk into a computable and quantitative customer expectation measurement model. Not only can researchers apply this theoretical expectation measurement model to investigate and recognize customer psychological status for the further academic research, but service firms can also use the results of the measurement model to deliver innovative service experiences.

\section{Background}

\section{Service experience}

Since customers are increasingly able to express their desires, enterprises face extremely variable customer needs. According to Pullman and Gross (2004), "an experience occurs when a customer has a sensation or knowledge acquisition resulting from interaction with different elements of a context created by a service firm." For instance, Disneyland proposes experiential and entertaining journeys for families that allow them to enjoy time together and imagine being in a fairy tale story. Service firms have to design appropriate service experiences for customers to achieve high customer satisfaction in the era of the experience economy (Pine and Gillmore, 1998). Voss et al. (2004) also noted the importance of experience-centric services and developed a series of service encounters and interactive activities for customers. Delivering and designing appropriate service experiences thus become a major trend for service firms seeking to enhance their competitiveness and fulfill customer needs by cooperation with customers to create value.

\section{Customer expectations}

The customer factor is crucial for service firms in achieving service innovation and ensuring business value and profits during ser- 
vice experience delivery. Customer expectations are considered to be customer wants, i.e., what customers feel service firms should offer over and above what they actually do offer. Hence, customer expectations regarding what they can acquire from service firms can define their expectations. Parasuraman et al. (1991) proposed that customer expectations comprise two levels: desired and adequate. Desired expectations represent the level of service a customer hopes to receive, defined as the level of service performance that the customer expects. Adequate expectations, a lower level of expectation, considered to be customer's acceptable level of performance (Zeithaml et al., 1993).

Parasuraman et al. (1991) argued that understanding customer expectations of service was important in delivering good service. Accordingly, customer expectation management is an important issue across different disciplines. For example, Calvert (2001) applied the survey method to analyze the relationship between customer expectations in different countries and cultures and library services. Lo et al. (2005) proposed a customer-based supply chain management framework based on customer expectations by the Delphi and interview methods. Kurtz et al. (1993) analyzed the influence of restaurant services on customer expectations using the survey method. Furthermore, Clow et al. (1997) applied the survey method to examine the relationship between service quality and customer expectations across diverse industries. However, these investigations were mostly based on using empirical methods to analyze customer expectations. Although these research methods employ systematical and discreet approaches to obtain the proper results, customer data is never real-time. Consequently, these non real-time social science studies suffer two limitations. First, human memories can become biased and vague over time. The reliability of these studies is decreased in terms of the accuracy of human memory. Second, it is difficult to understand and analyze actual customer behaviors based on static data obtained empirically, because such behaviors are extremely dynamic and complex due to different timings, situations or contexts.

Successfully managing customer expectations requires that service firms first understand customer expectations. Customer expectation measurement is an approach for estimating customer mental state. According to Parasuraman et al. (1991) and Zeithaml et al. (1993), the determinants and variations of expectations (namely, the zone of tolerance) are the key factors in measuring customer expectations. This study develops CEMM based on two factors.

\section{Fechner's Law}

Fechner's Law is then adopted to represent the relationship between external stimuli and human sensations. According to Fechner's Law, if the magnitude and type of the external stimulus are known, the magnitude of sensations can be calculated using the mathematical formula. Consequently, service firms thus can employ the expectation determinants to influence customer expectations. The expectation determinants can be considered the external stimuli and the customer expectations are likened to the sensations. This study applies Fechner's Law to customer expectation management within the services delivery to build an appropriate quantitative measurement model that can analyze and meet real customer needs to achieve business objectives.

In 1834 Ernst Heinrich Weber, a German physicist, presented a mathematical approach (Weber's Law) to measure the variation between two different stimuli (so-called Just Noticeable Difference, JND) which humans could be appropriately conscious of.

The equation of Weber's law is as follows,

$$
K=\Delta I / I \text { (Constant), }
$$

where $\triangle I$ denotes the difference threshold between two stimuli, I represents the initial stimulus intensity of a human and $\mathrm{K}$ is the constant of the specific sense that is the Weber proportion. For example, a human lifting 5 $\mathrm{kg}$ will notice that this requires some effort. However, if the lifter adds $0.01 \mathrm{~kg}$ and lifts 
again, they may not notice any difference between $5 \mathrm{~kg}$ and $5.01 \mathrm{~kg}$. If the lifter then continues to add weight, they will find the difference becomes noticeable at is $0.5 \mathrm{~kg}$. Moreover, a lifter lifting $10 \mathrm{~kg}$ on their first lift will find the just noticeable difference is $1 \mathrm{~kg}$. Notably, the ratio of $\triangle \mathrm{I} / \mathrm{I}(0.5 / 5=1 / 10=0.1)$ is the same in both these examples. However, Weber's Law does not explain how the subjective consciousness of a human changes with the variation of external stimulus intensity.

Consequently, Fechner proposed that using the just noticeable difference as the basic sensation unit is a feasible method of measuring the mental status of humans based on Web's Law. That is, summarizing each just noticeable difference segment can be considered the mental perception of humans. Fechner integrated the above equation to obtain another equation (so-called Fechner's Law or Weber-Fechner's Law) as follows (Thurstone, 1929),

$S=K * \log R$

where $S$ denotes the intensity of human mental perception, $R$ represents the intensity of the external stimulus and $K$ is a constant. This equation of Fechner's Law indicates a logarithmic relationship between mental perception and external stimulus (as shown in Figure 1). The logarithmic relationship describes that if the variation of the stimulus exhibits a geometric progression, the related mental perception of humans exhibits an arithmetic progression.

To summarize, the concept of Fechner's Law involves finding a method of describing the human mental state via external physical incentives. As mentioned earlier, it is difficult for service firms to understand customer expectations, which represent human psychological status. This study thus attempts to employ Fechner's Law to describe customer expectations mathematically. This study uses external stimuli (i.e., expectation tactics and service operations) to identify the representative value of customer expectations based on Fechner's Law.

\section{The capital requirements of operation risk}

According to Fechner's Law, stimuli are the critical influence on human perceptions. However, how to determine a representative stimulus value (that is, the combinations of the expectation determinants) for influencing customer expectations is extremely difficult given the limited past research. Operation risk thus can provide theoretical support to transform the expectation determinants into a representative stimulus value.

Operation risk has long been an important issue in traditional manufacturing. However, numerous industries gradually realized that operation risk would significantly influence their performance and profit, particularly in the banking industry. Banks are becoming increasingly complex and changeable owing to a highly competitive environment, diverse customer needs and advanced technology, potentially leading them to face higher risks. Consequently, the Basel Committee defined standard rules and norms for banks to reduce their operation risk. Furthermore, the New Basel Capital Accord (Basel Committee on Banking Supervision, 2001) defines operation risk as "the risk of direct or indirect loss resulting from inadequate or failed internal processes, people and systems or from external events." Operation risk is mainly based on the concept that banks must prepare additional capital to prevent such a risk. Accordingly, bank capital charges are essential for risk measurement and management.

According to the New Basel Capital Accord (Basel Committee on Banking Supervision, 2001), the equation of the Internal Models Approach is as follows,

Required Capital $=$

$\sum i \sum j[y(i, j) * E I(i, j) * P E(i, j) * L G E(i, j) * R P I(i, j)]$

Where $y$ represents each business line or loss type combination of banks, Exposure Indicator $(E I)$ represents the operation risk exposure of a particular business line, Probability of loss Event $(P E)$ represents the likelihood of losses, Loss Given Event (LGE) 
represents the ratio of transaction or exposure disbursed as loss, given that the event and Risk Profile Index $(R P I)$ represents the bank specific risk profile which illustrates bank capability to solve the risk problem. Furthermore, $i$ denotes business line and $j$ represents risk type.

Briefly, operation risk is determined using the concept of required capital (that is, probability) which includes several indicators for calculating and representing the risk value. The concept of operation risk can provide a clue for forming a representative value of stimulus intensity resulting from the expectation determinants. Hence, this approach can achieve enhanced integrity and rationality by using Fechner's Law of customer expectation management.

\section{Service operation design within service experience}

Delivering good service experiences to customers is necessary but difficult for service firms, especially in dynamic environments (Haeckel et al., 2003; Voss et al., 2008). Pullman et al. (2004) noted that service firms can increase customer loyalty and thus achieve high profits through developing their abilities in experience design. Consequently, how to provide customers with good service experiences is vital in academia and business. However, numerous key issues exist related to service experiences. Customer expectation management is a major factor influence on customer service experiences, as is service operation, which has long been discussed in different disciplines (Johnston, 1999; Roth and Menor, 2003; Rust et al., 1999; Voss et al., 2008). Service operations can be regarded as real service providers that customers can contact directly. Consequently, service firms deliver proper services to their customers by managing service operations. Service firms can successfully manage customer expectations by providing support in the form of good service operation settings.

\section{Environment issue}

Physical environment design has been continuously discussed in previous research on operations management. Bitner (1992) proposed three main environment dimensions (such as ambient conditions, space/function and signs, symbols and artifacts) which service organizations should consider while designing their physical purchase surroundings. Environmental design thus can influence not only service firm performance (Bitner, 1990) but also customer perceptions of service quality (Reimer and Kuehn, 2005). Furthermore, the main objective of environment design is to create atmospheric purchase surroundings for customers (Donovan and Rossiter, 1982; Kotler, 1973), and thus atmosphere is crucial in environmental design. Numerous empirical results clearly show that customers like to spend considerable time and money on purchasing and staying in the cordial, warm or comfortable surroundings (Bitner, 1990; Bitner, 1992; Donovan and Rossiter, 1982). Accordingly, service firms should prioritize basic service operation issues related to environmental design. Furthermore, environmental design should be extended to place boundaries on places encountered by customers.

\section{Employee issue}

Heskett et al. (1994) described that service firms should establish their own service-profit chains to increase customer numbers and potential benefits. Service-profit chains initially attempt to define service firm internal service quality which represents the importance relationship between frontline employees and external customers. Accordingly, employees are important in contacting customers directly in service encounters. External behaviors (such as warm talks, smiles or friendly treatment) of employees can influence customer perceptions (Lewis and Entwistle, 1990). Furthermore, service firms must also consider employee training, employee empowerment and service cultures in developing employment strategies (Bitner et al., 1994; Lewis and Entwistle, 1990). Service industries have procured the main economic activities in the Twenty-first Century, yet both virtual products (e.g., services) and physical products of a business still need employees to contact customers. That is, employees can be consi- 
dered a service experience delivery mode that enables customers to understand received value. Consequently, this study considers that employee external behaviors directly affect customer feelings and purchase behaviors.

\section{Technology issue}

To increase the abilities of matching customer needs, producing or delivering services, service firms can implement Information Technology to boost their competitive advantage. Service firms can not only raise and improve service performance (Meuter et al., 2000; Johnson et al., 2008) but can also enhance service quality (Meuter et al., 2000) through applying IT to service processes. Furthermore, employing IT within service encounters can enable customers to achieve higher satisfaction and thus help providers achieve their business objectives (Meuter et al., 2000; Johnson et al., 2008). Some research has indicated that it is essential for service firms to consider the reliability and adoption of IT-based services to increase customer usage and trust (Lee et al., 2003; Johnson et al., 2008). Information Technology supports service firms in performing their jobs accurately and effectively, thus increasing service quality and minimizing costs. Hence, service firms must deliver IT-based services within service encounters. Advanced technology can be considered a stimulus to enable customers to remain in an exciting and memorable experience.

To summarize, good management of customer expectations can help service firms achieve gains in the experience economy. However, previous research maintains that customer expectations are extremely difficult for service firms to understand. Correctly managing customer expectations is critical during service experience delivery. This study attempts to create a strong foundation of service operations to effectively and efficiently manage customer expectations. Service firms can utilize proper service operation strategies to maximize customer value during service experience delivery based on their capabilities, business goals, situations etc. Mean- while, this study can increase the relationship between service experiences and service operations to support the perspective of customer expectation management.

\section{Conceptual framework for designing excellent service experiences}

The conceptual framework used to design customer service experiences (as depicted in Figure 1) is built as described by Voss et al. (2008) and based on service operations. This conceptual framework represents the relationships among service operation design, expectation tactics and customer expectations during service experience delivery.

The objective for service firms is to deliver customers high quality service experiences. Consequently, service firms must consider two things. First, they must consider service functions. Service functionalities, such as time saving, convenience or problem solving, are basically prerequisites that must be provided to customers. Good quality services can boost customer satisfaction and thus increase repurchase likelihood. Hence, numerous previous articles have discussed the nature of services. For example, service quality is a key benchmark for evaluating service functionalities (Parasuraman et al. 1985). Service firms must also consider customer mentality, including customer expectations and emotions. Customer expectations indicate what customers expect to obtain from service firms (Parasuraman et al., 1991; Pit et al., 1994; Zeithaml et al., 1993). Hence, according to service firm capabilities and business goals, such firms can actively influence customer feelings (namely, the zone of tolerance) to accommodate existing services by utilizing expectation determinants that can be realized by expectation tactics. For example, when service firms have higher capabilities (such as capital, resources, or reputations), they narrow the zone of tolerance to increase the entry threshold for competitors. In contrast, the tolerance zone widens with reducing service firm capabilities.

Second, service firms must consider customer emotion. Customers respond positively to proper service stimuli when they exhibit plea- 


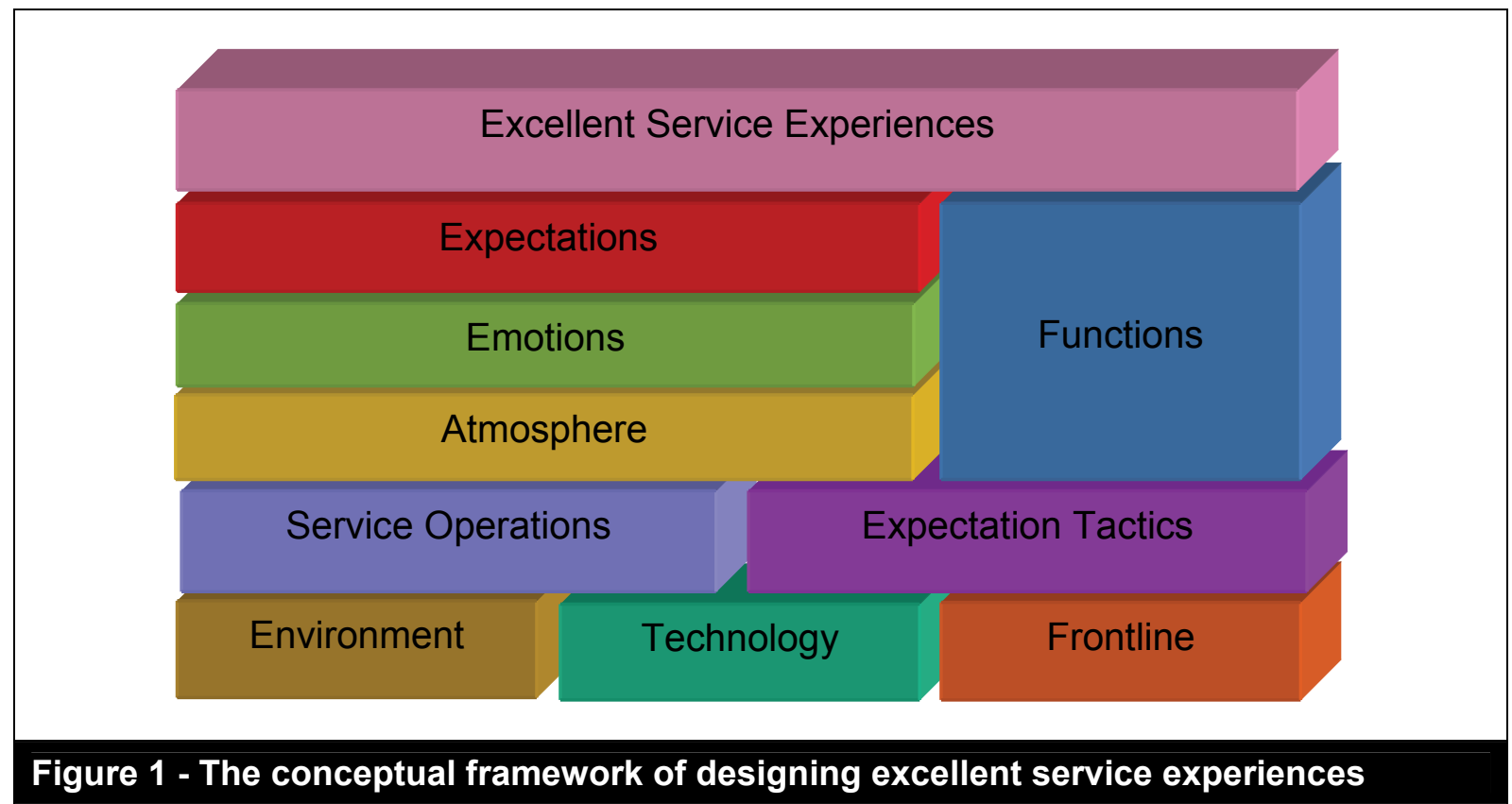

sure. For example, customers experiencing positive emotions (such as happiness, joy, excitement etc.) will spend more time and money in service surroundings (Donovan and Rossiter, 1982). Accordingly, both customer expectation management and emotions create concepts with service experience design to enhance service experience functions. Service operations and specific expectation tactics must be implemented by the environment, technology, and frontline designs to create a pleasant atmosphere and accomplish service functions related to certain attributes of service excellence. Consequently, since service experiences can comprise multiple segments, high-quality service experiences require an integral approach to effectively design the services and operation processes.

\section{Design of the Customer Expecta- tion Measurement Model}

This section delineates the design logic of CEMM grounded on the theoretical basis of Fechner's Law and operation risk.

\section{Applying Fechner's Law to CEMM}

According to Zeithaml et al. (1993), the expectation determinants can influence two cus- tomer expectation levels (desired and adequate expectation). This study details two customer expectation measurement models using Fechner's Law.

\section{Desired expectation measurement model}

Desired services are the high level expectation of customers which denotes the service customers hope to receive (Zeithaml et al., 1993). Furthermore, the desired expectation is highly stable. For example, some customers are concerned with high quality service or lower prices, and thus their basic needs cannot change. Consequently, the desired expectation measurement model can be applied by Fechner's Law. The equation of the desired expectation measurement model can be modified as follows,

$E_{D}=K * \log _{\alpha} S I$

where $E_{D}$ denotes the desired expectation value of the customer affected by the external stimuli, and SI represents the stimulus magnitude of the expectation determinants that is calculated via the concept of operation risk. Additionally, $\mathrm{K}$ is the constant representing customer type, which influences the model slope. This study employs five factors (for 


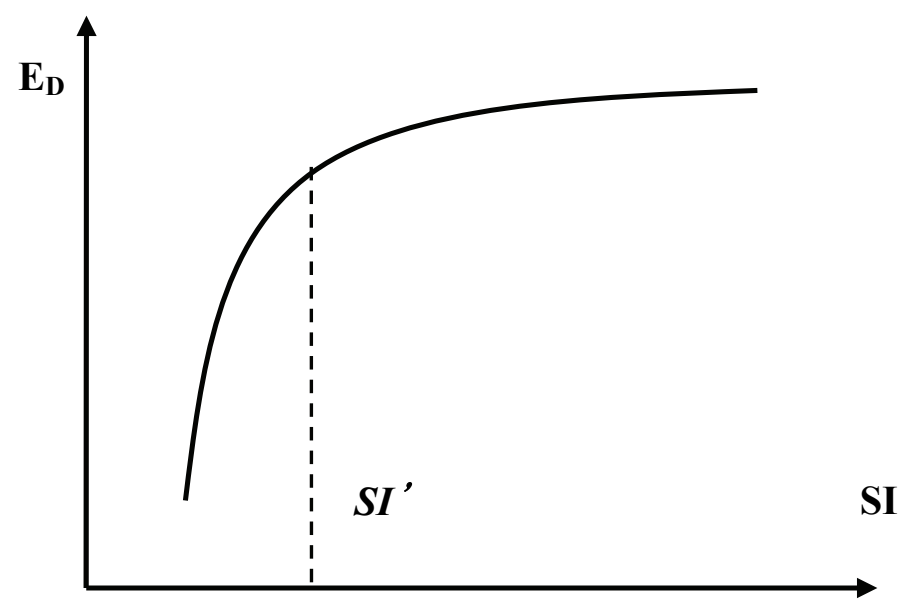

Figure 2 - Desired expectation measurement model

example, arrival, capability, effort, request, and subjective preference) to define different customer types (Frei, 2006). The mental perceptions of different customer types differ. For example, since customers with high scores in all five factors are considered customers who are easily affected by less external stimuli, these customers have larger $\mathrm{K}$. $\alpha$ is a label referring to the shape of the desired expectation measurement model.

Figure 2 clearly illustrates the curve of the desired expectation measurement model. When the stimuli intensity gradually increases, so too does customer desired expectation value. However, the desired expectation value increases slowly, while the stimuli intensity increases considerably. For instance, if the stimuli intensity exceeds a certain magnitude (SI'), the desired expectation value becomes stable.

\section{Adequate expectation measurement model}

Adequate services denote the lower end of customer expectations, and represent the minimum service level acceptable to customers (Zeithaml et al., 1993). Adequate customer expectations are frequently changeable and unstable contrasting with desired customer expectations. That is, adequate customer expectations are easily influenced by the expectation determinants. Notably, customer mental effects increase with the num- ber of determinants the service providers use. Consequently, this investigation defines the shape of the adequate expectation as nearly belonging to the $\mathrm{S}$ curve (as illustrated in Figure 3).

The curve means that the adequate expectation value increases with the external stimuli. After the stimuli intensity reaches a certain magnitude (SI'), even though the intensity exceeds this magnitude, the adequate expectation value would increase slowly and nearly be stable. The ultimate reason the adequate expectation steadies is that the adequate expectation achieves the desired expectation based on the concept of the zone of tolerance (Zeithaml et al., 1993). Namely, the zone of tolerance narrows during this period in terms of the overlap between the adequate and desired expectations.

According to Fechner's Law, the adequate expectation measurement model can be written in the form

$E_{A}=K * \log _{\beta} S I$

in which $E_{A}$ is the adequate expectation value of the customer influenced by the external stimuli, SI denotes the stimulus magnitude of the expectation determinants that are computed based on operation risk, and $\mathrm{K}$ represents customer type. $\beta$ is a label referring to the shape of the adequate expectation measurement model. 


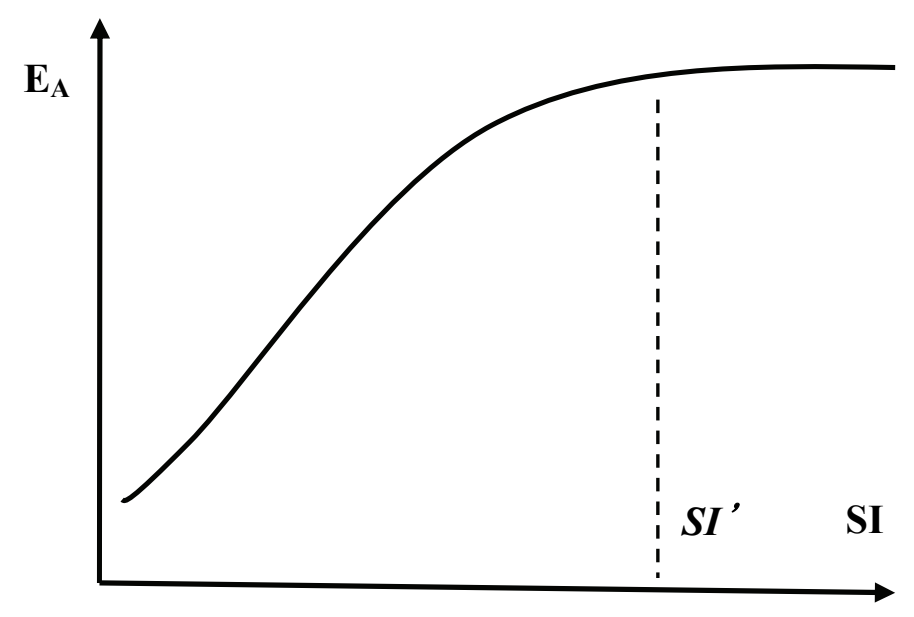

Figure 3 - Adequate expectation measurement model

\section{Applying operation risk to CEMM}

As mentioned earlier, the concept of required capital lies at the core of operation risk and is frequently implemented in the manufacturing and banking industries. To confront the huge capital losses resulting from operational risks, enterprises must prepare appropriate money (that is, required capital) in advance based on their capabilities, probabilities of loss events or risk exposure. Consequently, required capital represents the operation risks that enterprises face. This study applies operation risks to customer expectation measurement because customer expectations are simultaneously influenced by numerous stimuli from diverse sources. The stimuli within service experience delivery are combinations of expectation determinants rather than a single stimulus as described in Fechner's Law. How to aggregate the stimuli to represent a single stimulus in Fechner's Law thus is an important issue. By relating to operation risks, the stimulus intensity represents the influence of customer expectations. The change in customer expectations increases with the stimulus intensities that customers receive. Hence, this study utilizes operation risk to support stimuli performance.

This study refers to the formula of required capital and modifies the elements to form a new formula for calculating the magnitude of the stimuli intensity (SI). Accordingly, the formula of stimulus intensity can be written as follows,

$$
S I=U D I * P S E * A E V * C P I
$$

Table 1 lists the mapping relationship between the required capital and stimulus intensity formulas. This equation contains four key elements, as follows.

- Usage of determinant indicator (UDI): This indicator represents the influence of using the expectation determinants to influence customer expectations. According to Fechner's Law, human stimulus intensity becomes large if many irritants influence that individual. Namely, the more determinants providers propose, the larger the magnitude procured by the stimulus. Let $D=\left\{D_{1}, D_{2}, \ldots, D_{j}\right\}$ represent the set of all expectation determinants affecting customer expectations during service experience delivery, and let UDI $=\left\{U D I_{1}, U D I_{2}, \ldots, U D I_{n}\right\}$ comprise all combinations of the expectation determinants. For example, $\mathrm{UDI}_{1}$ includes implicit service promise and word-of-mouth communications and $\mathrm{UDI}_{2}$ represents the combination of transitory service intensifiers, perceived service alternatives and word-of-mouth communications. Each combination UDI contains a subset of the expectation determinants selected from 
Table 1 - The mapping table of the required capital and stimulus intensity formulas

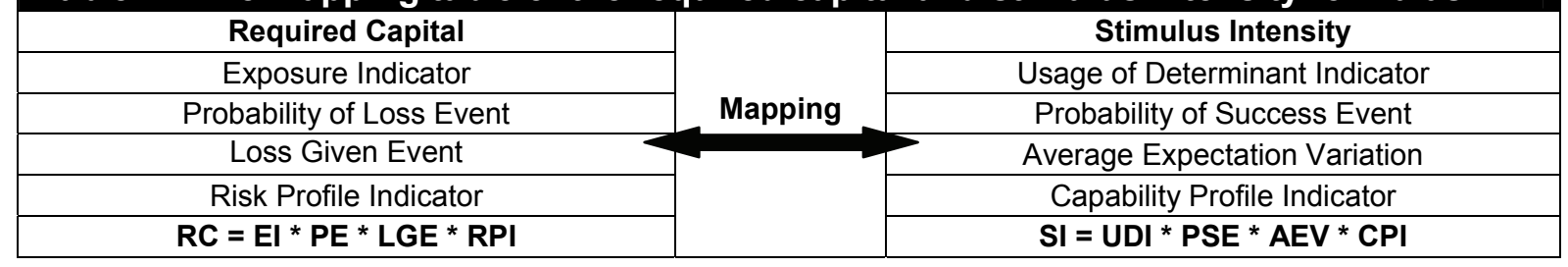

$D$. Let $W=\left\{W_{1}, W_{2}, \ldots, W_{l}\right\}$ represent the set of the weight of each combination UDI, which can influence service firm business goal. Each $D$ has an exclusive weight. Hence,

$$
U D I=\sum_{i=1}^{l} W_{l}
$$

- Usage of determinant indicator (UDI): This indicator represents the influence of using the expectation determinants to influence customer expectations. According to Fechner's Law, human stimulus intensity becomes large if many irritants influence that individual. Namely, the more determinants providers propose, the larger the magnitude procured by the stimulus. Let $D=\{D 1, D 2, \ldots, D j\}$ represent the set of all expectation determinants affecting customer expectations during service experience delivery, and let $\mathrm{UDI}=\{\mathrm{UDI} 1, \mathrm{UDI} 2, \ldots, \mathrm{UDIn}\}$ comprise all combinations of the expectation determinants. For example, UDI1 includes implicit service promise and word-of-mouth communications and UDI2 represents the combination of transitory service intensifiers, perceived service alternatives and word-of-mouth communications. Each combination UDI contains a subset of the expectation determinants selected from $D$. Let $W=\{W 1$, $W 2, \ldots, W I\}$ represent the set of the weight of each combination UDI, which can influence service firm business goal. Each D has an exclusive weight. Hence,

$$
U D I=\sum_{i=1}^{l} W_{l}
$$

- Average Expectation Variation (AEV): Each combination $U D I_{d}$ has its average expectation variation. The expectation variation denotes the difference between the initial and terminal expectations while providers implement the expectation determinants during each round. The total expectation variations are then accumulated and averaged to understand the significant effects that the expectation determinants can provoke. Consequently, if the average expectation variation of an $U D I_{d}$ is large, so too is the magnitude of the stimulus. Let $E V=\left\{E V_{1}, E V_{2}, \ldots, E V_{j}\right\}$ denote the set of values of expectation variation of an $U D I_{d}$. Moreover, Let $A E V$ $=\left\{A E V_{1}, A E V_{2}, \ldots, A E V_{j}\right\}$ represent the set of all values of the average expectation variation. The equation of average expectation variation can be represented as follows,

$$
A E V_{j}=\frac{\sum_{i=1}^{j} E V_{j}}{j}
$$

For instance, $A E V_{1}$ can be represented as 5 by calculating each result of the expectation variation resulting from the total data obtained by historical use of $\mathrm{UDI}_{1}$.

- Probability of Success Event (PSE): The definition of a success event that service firms attempt to utilize certain $U D I_{d}$ to calculate the average expectation variation. As mentioned above, the average expectation variation is accumulated based on each calculation of customer expectation. Hence, PSE calculates the probability of a success event by capturing and updating real time data. Different $U D I$ has its probability for achieving the average expectation. Let $P S E=\left\{P S E_{1}\right.$, $\left.P S E_{2}, \ldots, P S E_{n}\right\}$ denote the set of all probabilities of a success event, and let WUP represent willingness to use the specific UDI and NUP as the records of unwillingness to use the specific UDI. 
Design of the customer expectation measurement model in dynamic service experience delivery / Hsieh and Yuan

The probabilities of success events can be calculated as follows,

$P S E_{n}=\frac{W U P_{n}}{W U P_{n}+N U P_{n}}$

That is, if $W \mathrm{PP}_{1}$ is 80 records of using $\mathrm{UDI}_{1}$ and NUP ${ }_{1}$ is 20 records of unwillingness to use $\mathrm{UDI}_{1}$ then $\mathrm{PSE}_{1}$ can be represented as 0.8 .

- Capability Profile Indicator (CPI): According to the operation risk, the risk profile indicator evaluates the ability of a bank to deal with the operation risks. CEMM uses the capability profile indicator to assess service firm competence. When service firms have high capabilities (such as numerous resources, high capital or collaborative partnerships) the magnitude of the stimulus is increased. Additionally, the capability profile indicator should be defined according to the domain-specific applications. The equation of the capability profile indicator can be written as follows

$C P I=\sum_{i=1}^{n} W i * C i$

where $C_{i}$ denotes the competence indicators of the provider and $W_{i}$ represents the weights of each competence indicator. For example, the numbers of em- ployees, partners and production lines can be defined as competence indicators, with weights of $0.2,0.5$ and 0.3 , respectively. The competence indicators must first be normalized depending on the business goals and application domains, and are assigned scores of 85 , 70 and 90. The CPI thus is 79 $\left(0.2^{*} 85+0.5^{*} 70+0.3^{*} 90\right)$.

The above reveals a positive correlation between the stimuli intensity and individual indicators. To our knowledge, the stimuli intensity increases with the number of indicators. To represent the influences of four indicators, the stimuli intensity can be regarded as the multiplied results.

\section{Customer Expectation Measurement Model}

Following applying Fechner's Law and operation risks, CEMM (as shown in Figure 4) can be represented as follows. SI' and SI" respectively represent the magnitude threshold of the desired and adequate expectations. Furthermore, the design of $\alpha$ and $\beta$ clearly differentiates the desired and adequate expectation measurement models, since $\alpha$ and $\beta$ influence curve shape. Furthermore, CEMM for desired expectation can be written as follows (the dotted curve),

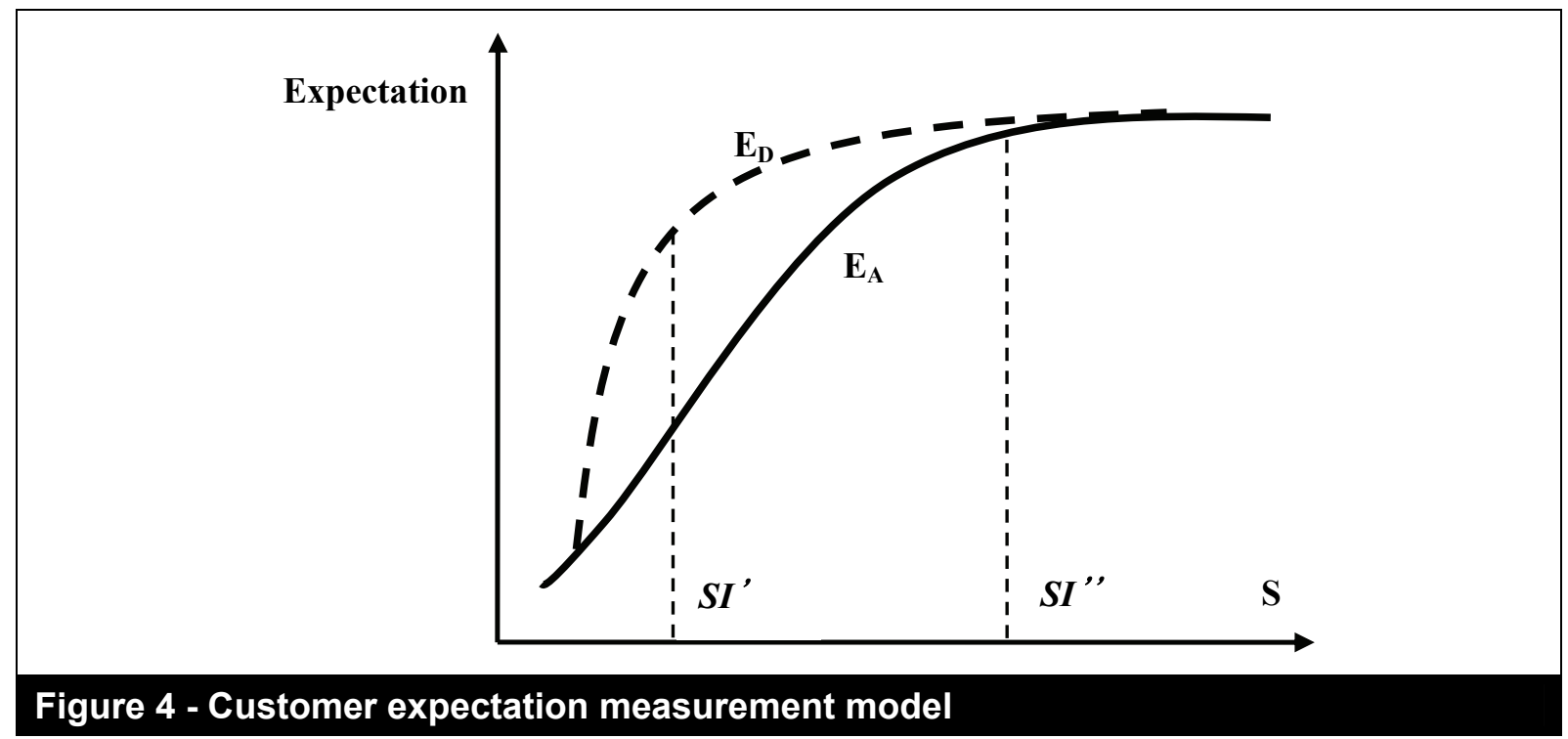




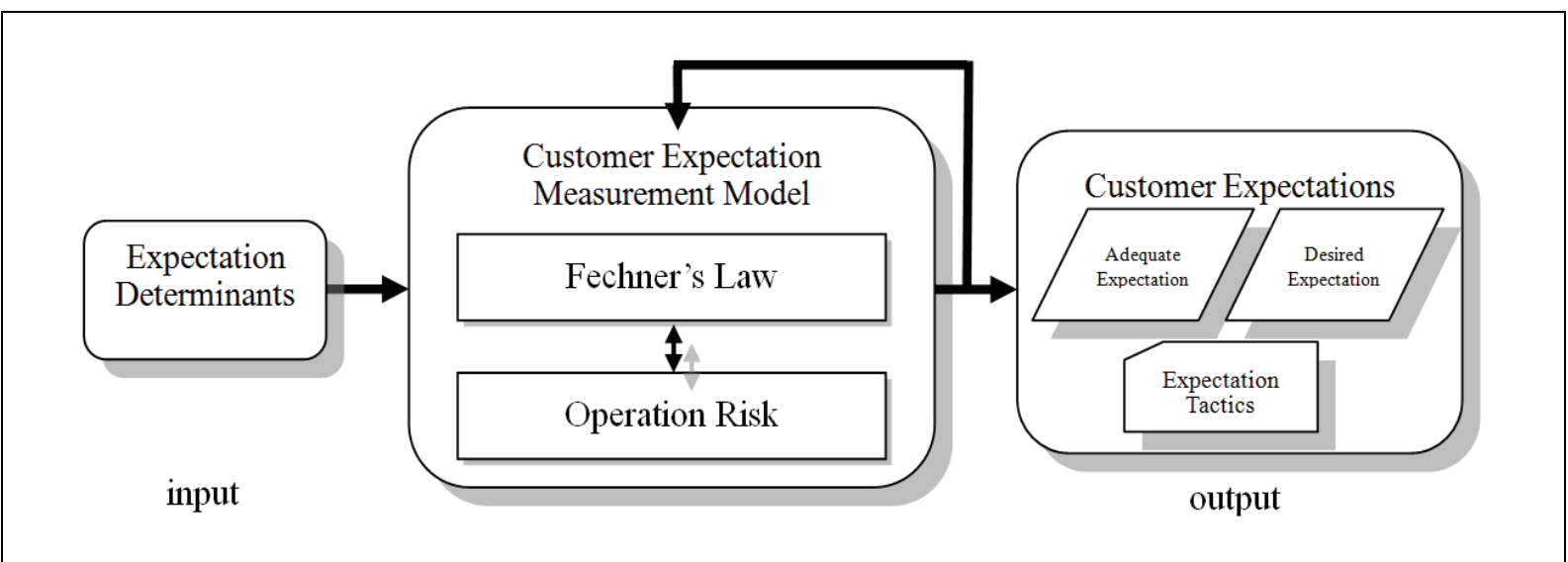

Figure 5 - The process of measuring customer expectations

$$
\left\{\begin{array}{l}
E_{D}=K * \log _{\alpha} S I \\
S I=U D I * P S E * A E V * C P I
\end{array}\right.
$$

CEMM for adequate expectation can be written as follows (the solid curve),

$$
\left\{\begin{array}{l}
E_{A}=K * \log _{\beta} S I \\
S I=U D I * P S E * A E V * C P I
\end{array}\right.
$$

\section{The process of measuring customer expectations}

Figure 5 represents the process of measuring customer expectations, which comprises three separate stages, including the expectation determinants, CEMM and customer expectations. Furthermore, during the customer expectations stage, the results of measuring customer expectations can be continuously fed back to the expectation measurement database which stores the data of all CEMM indicators.

\section{Expectation determinants stage}

The inputs of measuring customer expectations are the combinations of the expectation determinants that service firms propose may influence customer expectations. According to Zeithaml et al. (1993), the expectation determinants include enduring service intensifiers, personal needs, transitory service intensifiers, perceived service alternatives, customer self-perceived service role, situational factors, predicted service, explicit service promises, implicit service promise and word- of-mouth communications. Different combinations of expectation determinants exist and can be used as inputs to influence customer expectations in different situations (including time, customer expectation management objectives or provider capabilities). For example, when a service firm has a strong reputation and customer satisfaction with its services, that firm wishes to set the customer expectation management objective of increasing the adequate and desired expectations. Consequently, that firm can employ (i.e., explicit service promises) and a website recommendation service (namely, word-of-mouth communications) as a combination of the expectation determinants to influence and measure customer expectations.

\section{Customer expectation measurement model stage}

This step attempts to calculate the values of the desired and adequate service level expectations, when the customer contacts external stimuli. First, this study defines the objectives of managing customer expectations, including adequate increase in expectations, adequate reduction in expectations, desired increase in expectations, and desired reduction in expectations by extending the model of Zeithaml et al. (1991). According to these objectives and the combinations of the expectation determinants (that is, the stimulus), applying the stimulus intensity formula involves calculating the stimuli value using four indicators (i.e., UDI, PEV, EV and CPI) based on 
the operation risk. Second, after obtaining the stimuli value, CEMM is applied to compute the adequate or desired expectation value based on Fechner's Law.

\section{Customer expectations stage}

Accordingly, the outputs used to measure customer expectations contain the adequate expectation value, desired expectation value and list of expectation tactics. Once service firms understand actual customer expectations, they can use the outputs to propose suitable services and thus help customers achieve their business objectives. Additionally, the expectation tactics list, which is obtained from the database, provides service firms with a reference for proper service delivery. This study defines the expectation tactic as a service type that is mapped and related to an expectation determinant that directly or indirectly influences customer expectations. Service firms can employ appropriate expectation tactics suggested by CEMM to influence customer expectations. After service firms implement the expectation tactics, they must store the values of expectation variation and their capabilities indicators in the expectation measurement database. Consequently, CEMM can reflect actual customer expectations based on the feedback control.

\section{Scenario demonstration}

Hevner et al. (2004) proposed five evaluation methods (for example, the observational, analytical, experimental, testing and descriptive approaches) to evaluate the utility and quality of information system research. Scenario demonstration is one descriptive approach for conceptually delineating research. This study thus employs a B2C scenario of the exhibition service system to demonstrate the utility of CEMM.

Generally, highly capable exhibitors (such as SONY) must increase visitor expectation levels to achieve customer franchise, and can provide visitors with useful and appropriate services (such as exhibitor-recommendation service, advertisement information service, ebusiness card exchange service, or warranty service) to meet customer needs. SONY de- livers services to a visitor within a single encounter through the exhibition service system. Hence, the combination of delivered services (such as e-business card exchange service and warranty service) is represented in the form of the UDI. Meanwhile, the exhibition service system can analyze data related to the successful probability of using delivered

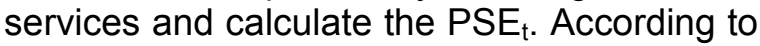
these services, the exhibition service system can also compute the average expectation value $A E V_{t}$ of using specific services. The exhibition service system can also yield the value of exhibitor capability $\left(\mathrm{CPI}_{\mathrm{t}}\right)$ based on existent human resources, technology level, service category or capital. The exhibition service system immediately transforms the four values into stimulus intensity $\left(\mathrm{SI}_{\mathrm{t}}\right)$ value to calculate visitor expectations. Furthermore, visitors can generally be divided into diverse classifications representing $\mathrm{K}$. Consequently, the service exhibition system can acquire the values of two expectation levels (i.e., $\mathrm{E}_{\mathrm{D}}$ and $\left.E_{A}\right)$. When SONY realizes visitor expectation values, it can flexibly modulate proper services to increase visitor expectations. That is, CEMM can enable exhibitors to deliver innovative service experience by closely grasping visitor wants in real time during service experience delivery.

\section{Discussion}

\section{The usage and feasibility of CEMM}

The basic idea of this study involves how service firms understand customer expectations in real time while delivering and designing services. The solution proposed in this study is CEMM. Consequently, this study addresses the following significant advantages of the application of CEMM. First, it is difficult for service firms to understand customer mental status during service experience delivery. For instance, service firms cannot immediately ask customers to share their expectations and perceptions via questionnaires after offering a service. That could increase business costs and hassle for customers. Consequently, the best solution is to transform customer expectations into computable numbers that service firms can easily under- 


\begin{tabular}{|c|c|c|c|c|}
\hline \multicolumn{5}{|c|}{ Table 2 - The comparison of measuring customer expectation approaches } \\
\hline & Timing & Context & Flexibility & Cost \\
\hline CEMM & During service experience delivery & Dynamic & High & Below Medium \\
\hline Survey & After perceiving service experiences & No & Low & High \\
\hline Interview & After perceiving service experiences & No & Low & High \\
\hline
\end{tabular}

stand. CEMM provides service firms with a quantitative mechanism for defining and understanding customer expectations. Second, in terms of stability and precision, CEMM can be designed as a learning mechanism that is continuously trained and modified using the accumulated data (e.g., $\mathrm{E}_{\mathrm{D}}, \mathrm{E}_{\mathrm{A}}$, UDI, AVI, and PSE). That is, CEMM can dynamically adjust the existing values of the aforementioned indicators to calculate actual customer expectations.

Furthermore, the practical considerations surrounding the application of CEMM are as follows. First, the inputs and indicators of CEMM are designed for simplicity and need. For example, in Figure 2, the combination of the expectation determinants is the only input of CEMM which directly and significantly influences customer expectations. Service firms need only define their existing services related to the expectation determinants as inputs. The same idea applies for other indicators. Second, the explanations of indicators can be extended or narrowed according to application domain. For instance, the CPI indicator in the hospital firms includes the numbers of doctors and nurses or the reputation of the hospital, but the capital, production lines and numbers of customers can be represented as the $\mathrm{CPI}$ indicator in the manufacturing firms. Finally, to gather real time data from customers, a device (such as handhelds) for immediately sensing and obtaining customer responses (e.g., accepting or rejecting delivered services) is necessary during service experience delivery. Such devices can be considered a tool for communication between service firms and customers. Accordingly, service firms can easily apply CEMM in real time service contexts.

In previous research, service firms and academic researchers mostly used survey and interview approaches to obtain customer expectations. Table 2 compares three ap- proaches for measuring customer expectations. This study attempts to utilize four indicators to analyze the measurement performance of these three approaches. Timing represents when service firms can measure customer expectations. Survey and interview are only used following customers perceive service experiences, yet CEMM can be used to acquire real time customer expectations while service firms offer service experiences. Context presents environmental variations, including customer needs, provider strategies or competitors. CEMM is superior to the survey and interview approaches in dealing with the dynamic service context given the short duration of a service experience. Given the advantages of timing and context, CEMM also has high flexibility in helping service firms select suitable services for immediately meeting customer needs. Survey and interview feedback is late in improving service experience delivery given the need of customers to finish all service experiences. Finally, for the cost indicator, survey and interview offer a means of spending more time and money to collect and inquire customer expectations. However, CEMM is built once and used continuously which can clearly reveal the high usage and feasibility of CEMM.

\section{Implications for service experience de- livery}

Ojasalo (2001) noted that enterprises must effectively manage customer expectations to achieve their long-term business goals. Furthermore, service firms must meet customer expectations to satisfy their customers and increase their performance (Rust et al., 1999). CEMM is based on expectation theory, Fechner' Law and the concept of operation risk, and aims to be an innovative and theoretical mechanism for precisely understanding customer expectations. Service firms not only have efficient service performance, but also reduce additional fees (such as including hu- 
man, time or operational costs). Consequently, service firms focus on their services and business strategies.

Furthermore, the service experience delivery system is also needed to take account of service operations (Roth and Menor, 2003). Although customer expectation management is crucial for realizing customer wants during service experience delivery, there is insufficient evidence that customers exhibit specific purchasing behaviors as a result of achieving suitable services. Increasing customer expectation management efficiency requires employing service operation design. As mentioned earlier, service operation elements include the environment arrangement, advanced technology and frontline treatment that can generate atmospheric surroundings that give customers a comfortable and pleasant feeling. While service firms deliver proper services to influence customer expectations, they can easily meet customer needs particularly in atmospheric surroundings. That is, one of the key business goals of service firms is to increase profits. Service firms should implement effective customer expectation management based on good service operations settings. Consequently, this study attempts to ensure the success of implementing customer expectation management through considering service operations.

Thus, empirical study, such as the survey method, is an important research method for investigating and understanding phenomenon formation. However, Homer (1993) described how respondent self-report surveys can obtain biases as a result of incorrect reports. Consequently, CEMM is a real time mechanism, which means customer data is continuously updated and gathered during service experience delivery. Service firms can immediately obtain the latest information to decide on service strategies to propose for customers. Undoubtedly service firms can deliver appropriate services to their customers in real time. Moreover, customer experience management is the basic form of customer relationship management (Meyer and Schwager, 2007). The real time measurement model can help service firms identify their target cus- tomers and maintain their relationships to achieve their business and personal objectives.

\section{Conclusions}

Service experience innovation is the key that can assist service firms in designing services customers want. Previous studies investigated how to deeply understand customer needs; however to date no effective and useful mechanism has been developed to solve this problem. Most previous research used empirical methods to analyze customer behaviors, yet the processes involved in delivering service experiences are dynamic rendering customer needs or feelings unstable and changeable. Accordingly, this study proposes a systematical and quantitative model for measuring customer expectations during service experience delivery based on theoretical support (such as expectation theory, Fechner's Law and operation risk). This study tries to employ this mechanism to examine customer expectations and behaviors in real time. Therefore, CEMM can be implemented as a creative service for service innovation that reveals customer mental state to providers.

This study makes the following contributions. First, customer expectation is difficult to quantify in terms of diverse human psychology. This study attempts to establish a computable model comprising key indicators and theories to provide a foundation for future research. Finally, CEMM can be applied in real time situations, enabling service firms to immediately understand customer expectations and also to adjust to deliver suitable services to customers to match customer needs and achieve high customer satisfaction during service experience delivery. However, CEMM still must be empirically evaluated and verified, and a simulation method also provides a workable approach to test the validity and reliability of CEMM. CEMM is designed as a real service system for an application (such as the exhibition service system in the B2C scenario). Gathering field data from real customers who utilize the service system is necessary to assess the reliability of CEMM and improve its shortcomings. 
Design of the customer expectation measurement model in dynamic service experience delivery / Hsieh and Yuan

\section{References}

Basel Committee on Banking Supervision. (2001). "Operational Risk," Basel Report, January, 1-30.

Bitner, M.J. (1990). "Evaluating Service Encounters: The Effects of Physical Surroundings and Employee Responses," Journal of Marketing, 54, 69-82.

Bitner, M.J. (1992). "Servicescapes: The Impact of Physical Surroundings on Customers and Employees," Journal of Marketing, 56(2), 57-71.

Bitner, M.J., Booms, B.H. and Mohr, L.A. (1994). "Critical Service Encounters: The Employee's Viewpoint," Journal of Marketing, 58(4), 95-106.

Calvert, P.J. (2001). "International Variations in Measuring Customer expectations," Library Trends, 49(4), 732757.

Clow, K.E., Kurtz, D.L., Ozment, J. and Ong, B.S. (1997). "The Antecedents of Consumer Expectations of Services: An Empirical Study across Four Industries," Journal of Service Marketing, 11(4), 30-248.

Donovan, R.J. and Rossiter, J.R. (1982). "Store Atmosphere: An Environmental Psychology Approach," Journal of Retailing, 58(1), 34-37.

Frei, F. (2006). "Breaking the trade-off between efficiency and service", Harvard Business Review, 84(11), 92101.

Gupta, K. and Stewart, D. (1996). "Customer satisfaction and customer behavior: The differential role of brand and category expectations," Marketing Letters, 7(3), 249-263.

Haeckel, S.H., Carbone, L.P. and Berry, L.L. (2003). "How to Lead the Customer Experience," Marketing Management, 12(1), 18-24.
Heskett, J.L., Jones, T.O., Loveman, G.W., Jr., Sasser, W.E. and Schlesinger, L.A. (1994). "Putting the ServiceProfit Chain to Work," Harvard Business Review, 72(2), 164-174.

Hevner, A.R., March, S.T., Park, J. and Ram, S. (2004), "Design science in information systems research," MIS Quarterly, 28(1), 75-105.

Homer, J.B. (1993). "A System Dynamics Model of National Cocaine Prevalence," System Dynamics Review, 9(1), 49-78.

Johnston, R. (1999). "Service Operations Management: Return to Roots," International Journal of Operations \& Production Management, 19(2), 104124.

Johnson, D., Bardhi, F. and Dunn, D. (2008). "Understanding How Technology Paradoxes Affect Customer Satisfaction with Self-Service Technology: The Role of Performance Ambiguity and Trust in Technology," Journal of Psychology \& Marketing, 25(5), 416443.

Kotler, P. (1973). "Atmospherics as a Marketing Tool," Journal of Retailing, 49(4), 48-64.

Kurtz, D.L. and Clow, K.E. (1993). "Managing Consumer Expectations of Services," The Journal of Marketing Management, 2(2), 19-25.

Lee, E., Lee, J. and Eastwood, D. (2003). "A Two-Step Estimation of Consumer Adoption of Technology-Based Service Innovations," Journal of Consumer Affairs, 37(2), 256-82.

Lewis, B. and Entwistle, T. (1990). "Managing the Service Encounter: A Focus on the Employee," International Journal of Service Industry Management, 1(3), 41-52. 
Design of the customer expectation measurement model in dynamic service experience delivery / Hsieh and Yuan

Lo, V.H.Y., Sculli, D., Yeung, A.H.W. and Yeung, A.C.L. (2005). "Integrating Customer Expectation into the Development of Business Strategies in a Supply Chain Environment," International Journal of Logistics: Research and Applications, 8(1), 37-50.

Meuter, M.L., Ostrom, A.L., Roundtree, R.I. and Bitner, M.J. (2000). "SelfService Technologies: Understanding Customer Satisfaction with Technology-Based Service Encounters," Journal of Marketing, 64(3), 50-64.

Meyer, C. and Schwager, A. (2007). "Understanding Customer Experience," Harvard Business Review, 85(2), 117-126.

Ojasalo, J. (2001). "Managing Customer Expectations in Professional Services," Managing Service Quality, 11(3), 200-212.

Schurter, T. and Towers, S. (2006). Customer Expectation Management: Success without Exception, MeghanKiffer Press, Florida, USA.

Spreng, R., MacKenzie, S. and Olshavsky, R. (1996). "A re-examination of the determinants of consumer satisfaction," Journal of Marketing, 60, 15-32.

Tam., J.L.M. (2007). "Managing customer expectations in financial services: Opportunities and challenges," Journal of Financial Services Marketing, 11(4), 281-289.

Parasuraman, A., Berry, L.L. and Zeithaml, V.A. (1991). "Understanding Customer Expectations of Service," Sloan Management Review, 32(3), 39-48.

Parasuraman, A., Zeithaml, V.A. \& Berry, L.L. (1985). "A Conceptual Model of Service Quality and Its Implications for Future Research," Journal of Marketing, Fall, 41-50.
Peppers, D., Rogers M., and Dorf, B. (1999). "Is Your Company Ready for OneTo-One Marketing?" Harvard Business Review, 77(1), 151-160.

Pine, B.J. and Gilmore, J.H. (1998). "Welcome to the experience economy", Harvard Business Review, 76(4), 97105.

Pitt, L.F. and Barbara, J. (1994). "Management of Customer Expectations in Service Firms: A Study and a Checklist," The Service industries Journal, 14(2), 170-189.

Pullman, M.E., and Gross, M.A. (2004). "Ability of Experience Design Elements to Elicit Emotions and Loyalty Behaviors," Decision Science, 35(3), 531-576.

Reimer, A. and Kuehn, R. (2005). "The Impact of Servicescape on Quality Perception," European Journal of Marketing, 39(7), 785-808.

Roth, A.V. \& Menor, L. (2003). "Designing and Managing Service Operations: Introduction to the Special Issue," Production and Operations Management, 12(2), 141-145.

Rust, R.T., Inman, J.I., Zahorik, J. and Jia, A. (1999). "What You Don't Know About Customer-perceived Quality: The Role of Customer Expectation Distributions," Marketing Science, 18(1), 77-92.

Sundbo, J. (1997). "Management of Innovation in Services," The Services Industries Journal, 17(3), 432-455.

Thurstone, L.L. (1929). "Fechner's Law and the Method of Equal Appearing Intervals," Journal of Experimental Psychological, 12, 214-224.

Voss, C.A. (2004). Trends in the Experience and Service Economy: The Experience Profit Cycle, London Business School. 
Voss, C.A., Roth, A.V. and Chase, R.B. (2008). "Experience, Service Operations Strategy, and Services as Destinations: Foundations and Exploratory Investigation," Production and Operations Management, 17(3), 147-266.

\section{About the Authors}

Yen-Hao Hsieh is an Assistant Professor in the Department of Information Management, College of Health and Information at Chia Nan University of Pharmacy and Science in Taiwan. He received his $\mathrm{PhD}$ in Management Information Systems from National Chengchi University. His research interests include service science, customer expectation management and service experience design. Yen-Hao Hsieh is the corresponding author and can be contacted at: yhhsiehs@mail.chna.edu.tw
Zeithaml, V.A., Berry, L.L. and Parasuraman, A. (1993). "The Nature and Determinants of Customer Expectations of Service," Journal of the Academy of Marketing Science, 21(1), 1-12.

Soe-Tsyr Yuan is Director of the Service Science Research Center and a Professor in the Department of Management Information Systems, College of Commerce at National Chengchi University in Taiwan. She received her $\mathrm{PhD}$ in Computer Science from Oregon State University. Her research interests include service science, service design, intelligent agents, data mining, and E/M-commerce. Soe-Tsyr Yuan can be contacted at: yuans@mis.nccu.edu.tw 